Check for updates

Cite this: RSC Adv., 2018, 8, 28261

Received 14th May 2018

Accepted 20th July 2018

DOI: $10.1039 / c 8 r a 04083 d$

rsc.li/rsc-advances

\section{Regio-selective and stereo-selective hydrosilylation of internal alkynes catalyzed by ruthenium complexes $\uparrow$}

\author{
Wenhao Dai,,$^{\text {ab }}$ Xiaowei Wu, $\neq^{\text {bc }}$ Chunpu Li, ${ }^{b}$ Rui Zhang, ${ }^{\text {bc }}$ Jiang Wang ${ }^{b}$ \\ and Hong Liu (D) *ab
}

In this study, ruthenium(॥)-catalyzed direct hydrosilylation of internal alkynes with high regio-selectivity and stereo-selectivity is reported. This title transformation led to various vinylsilanes in good to excellent yields. This approach features mild reaction conditions, low catalyst loading, air-stability, and good functional group tolerance. Furthermore, gram-scale preparation and some transformations of vinylsilanes were carried out, which further underscored its synthetic utility and applicability.

\section{Introduction}

Vinyl-metal reagents play a key role in organic synthesis. Among the available vinyl-metal reagents, silicon-based reagents are increasingly important. Vinylsilanes are versatile synthetic building blocks, because of their minimal toxicity, low cost, ease of handling, and tendency to undergo different kinds of transformation. ${ }^{1}$ Among the available methods for preparation of vinylsilanes, the hydrosilylation of alkynes is the most powerful strategy because it is direct and atom-economical, and it offers the potential to control the regio-selectivity and stereoselectivity. ${ }^{2-4}$ Although there are many methods for the hydrosilylation of terminal alkynes, particularly for the preparation of cis- and trans- $\beta$-vinylsilanes, the regio-selective and stereoselective hydrosilylation of internal alkynes still remains a great challenge due to their low reactivity and close similarity

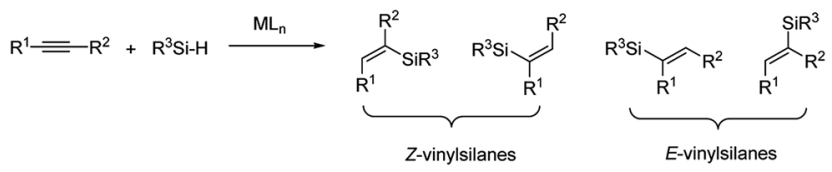

Fig. 1 Four isomeric addition products.

\footnotetext{
${ }^{a}$ School of Pharmacy, China Pharmaceutical University, Nanjing 210009, Jiangsu, China

${ }^{b}$ Key Laboratory of Receptor Research, Shanghai Institute of Materia Medica, Chinese Academy of Sciences, 555 Zu Chong Zhi Road, Shanghai, 201203, China. E-mail: hliu@simm.ac.cn

'University of Chinese Academy of Sciences, No. 19A Yuquan Road, Beijing 100049, China

$\dagger$ Electronic supplementary information (ESI) available: Data for new compounds and experimental procedures. See DOI: 10.1039/c8ra04083d

$\ddagger$ Wenhao Dai and Xiaowei Wu contributed to this work equally.
}

in terms of electronic and steric properties to the acetylenic substituents. ${ }^{5-7}$ Non-selective hydrosilylation of internal alkynes would potentially give four isomeric addition products (Fig. 1).

To address the difficulty of regiocontrol in the hydrosilylation of unsymmetrical (internal) alkynes, a directing group (DG) was introduced into an unsymmetrical alkyne to control their regio-selectivity of the hydrosilylation. Zakarian $^{6 \boldsymbol{d}}$ and co-workers developed the silylation of internal alkyne and sequential iododesilylation with high

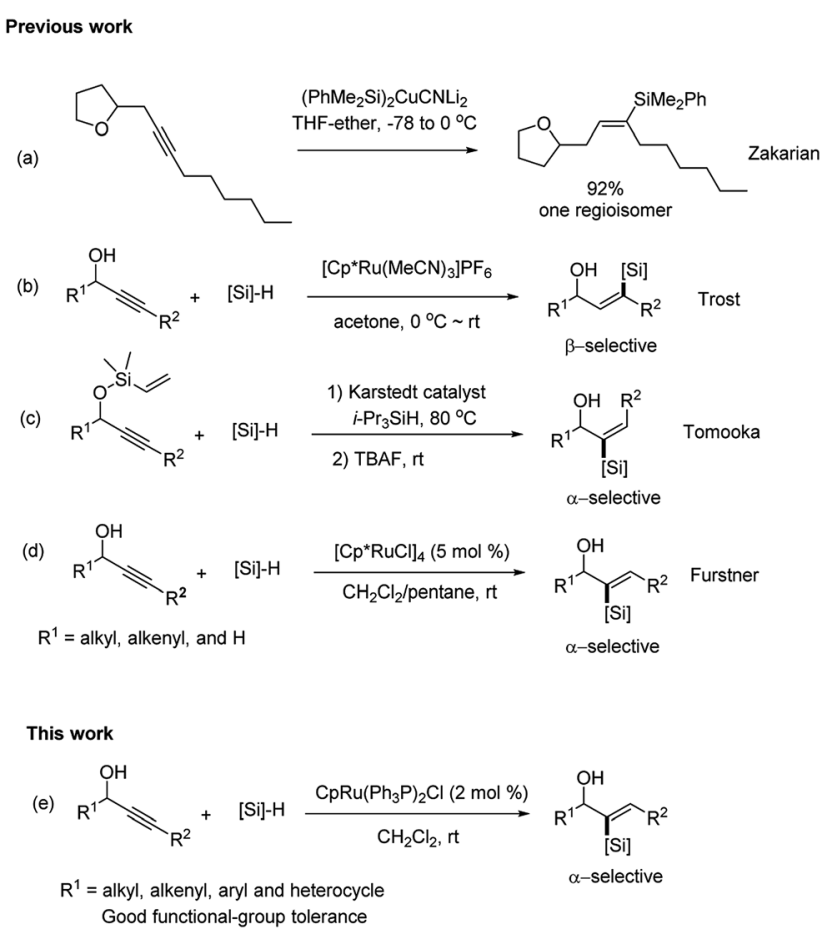

Scheme 1 Directed hydrosilylation of internal alkynes. 
Table 1 Optimization of reaction conditions ${ }^{a}$

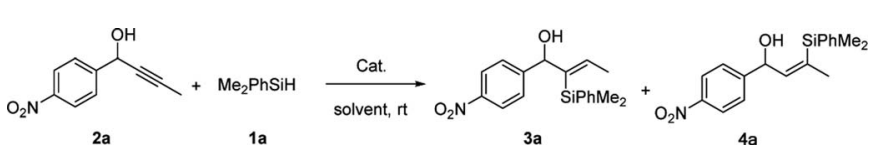

\begin{tabular}{lllll}
\hline Entry & Catalyst $(\mathrm{mol} \%)$ & Solvent & $\alpha: \beta$ ratio $^{b}$ & Yield $^{c}(\%)$ \\
\hline 1 & $\mathrm{CpRu}\left(\mathrm{Ph}_{3} \mathrm{P}\right)_{2} \mathrm{Cl}(5)$ & THF & $82: 18$ & 68 \\
2 & $\mathrm{CpRu}\left(\mathrm{Ph}_{3} \mathrm{P}\right)_{2} \mathrm{Cl}(5)$ & Toluene & $94: 6$ & 59 \\
3 & $\mathrm{CpRu}\left(\mathrm{Ph}_{3} \mathrm{P}\right)_{2} \mathrm{Cl}(5)$ & Acetone & $79: 21$ & 65 \\
4 & $\mathrm{CpRu}\left(\mathrm{Ph}_{3} \mathrm{P}\right)_{2} \mathrm{Cl}(5)$ & $\mathrm{CH}_{2} \mathrm{Cl}_{2}$ & $95: 5$ & 94 \\
5 & {$\left[\left\{\mathrm{RuCl}{ }_{2}(p-c y m e n e)\right\}_{2}\right](5)$} & $\mathrm{CH}_{2} \mathrm{Cl}_{2}$ & - & $-{ }^{d}$ \\
6 & {$\left[\mathrm{Cp} * \mathrm{RuCl}_{4}(5)\right.$} & $\mathrm{CH}_{2} \mathrm{Cl}_{2}$ & $92: 8$ & 83 \\
7 & $\mathrm{CpRu}\left(\mathrm{Ph}_{3} \mathrm{P}\right)_{2} \mathrm{Cl}(2)$ & $\mathrm{CH}_{2} \mathrm{Cl}_{2}$ & $95: 5$ & $94(94)$ \\
8 & $\mathrm{CpRu}\left(\mathrm{Ph}_{3} \mathrm{P}\right)_{2} \mathrm{Cl}(1)$ & $\mathrm{CH}_{2} \mathrm{Cl}_{2}$ & $95: 5$ & 89 \\
9 & $\mathrm{CpRu}\left(\mathrm{Ph}_{3} \mathrm{P}\right)_{2} \mathrm{Cl}(2)$ & $\mathrm{CH}_{2} \mathrm{Cl}_{2}$ & $91: 9$ & $86^{e}$ \\
10 & {$\left[\mathrm{CpRu}\left(\mathrm{Ph}_{3} \mathrm{P}\right)(\right.$ tht $\left.)\right] \mathrm{BF}_{4}(5)$} & $\mathrm{CH}_{2} \mathrm{Cl}_{2}$ & $22: 78$ & 18
\end{tabular}

${ }^{a}$ Reaction conditions: $1 \mathrm{a}(0.24 \mathrm{mmol}), \mathbf{2 a}(0.2 \mathrm{mmol})$, in $2 \mathrm{~mL}$ solvent at room temperature, Ar atmosphere for $12 \mathrm{~h} .{ }^{b}$ Determined by ${ }^{1} \mathrm{H}$ NMR analysis of the crude reaction mixtures. ${ }^{c} \mathrm{NMR}$ yields using $\mathrm{CH}_{2} \mathrm{Br}_{2}$ as an internal standard, isolated yields in parenthesis. ${ }^{d}$ This entry's major product is $\alpha$-selective cis- hydrosilylation (see NOE analysis in SI). ${ }^{e}$ 1a $(0.24 \mathrm{mmol}), 2 \mathrm{a}(0.2 \mathrm{mmol})$, in $2 \mathrm{~mL}$ solvent at room temperature under air atmosphere for $12 \mathrm{~h}$.

regioselectivity. The regioselectivity is guided by coordination of the silylcupration reagent to hydroxy or alkoxy groups in the substrate (Scheme 1a). In the early 2000s, Trost ${ }^{8}$ and co-workers reported the regio-selective trans-hydrosilylation of propargylic alcohols catalyzed by the cationic complex $\left[\mathrm{Cp} * \mathrm{Ru}(\mathrm{MeCN})_{3}\right] \mathrm{PF}_{6}$, which resulted in $\beta$-selective silylation at the alkyne carbon (Scheme 1b). The introduction of a hydroxyl group at the propargylic position is crucial to control the regioselectivity of hydrosilylation. In addition, a carbonyl group has been also shown to direct hydrosilylation of internal alkynes to provide $\alpha$-vinylsilanes. While, the regio-selectivity largely depends on the electronic effect. ${ }^{7 d}$ On the contrary, the examples of $\alpha$-selective hydrosilylation of unbiased unsymmetrical internal alkynes are very limited, ${ }^{7 c, 7 e, 9}$ especially for the propargylic alcohol substrates. To date, selective hydrosilylation on the $\alpha$-carbon of propargylic alcohols are rarely reported. In 2011, Tomooka's group ${ }^{7 c}$ described Pt-catalyzed $\alpha$-selective hydrosilylation of unsymmetrical alkynes using a dimethylvinylsilyl (DMVS) group as the directing group (Scheme 1c). However, the substrate scope of this method was limited for the primary alcohols. More recently, Fürstner ${ }^{9 a, 9 b, 9 c}$ and co-workers disclosed that $[\mathrm{Cp} * \mathrm{RuCl}]_{4}$ also catalyzed the hydrosilylation of propargylic alcohols to form $\alpha$-vinylsilanes with a high degree of regioselectivity (Scheme 1d). While, the $\mathrm{R}^{1}$ part of propargylic alcohols was alkyl, alkenyl and $\mathrm{H}$. In view of the importance of the broad synthetic utility of vinylsilanes, we are interested in developing another efficient catalyst for $\alpha$-selective hydrosilylation of propargylic alcohols. Herein, we describe a new method for the hydrosilylation of differentially propargyl alcohols with a new ruthenium complex under mild conditions (Scheme 1e). The transformation is highly
Table 2 Propargylic alcohol scope..$^{a, b, c}$

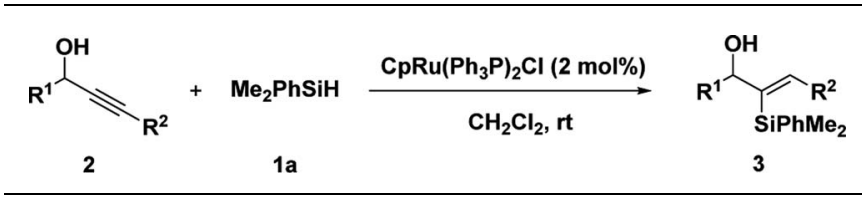

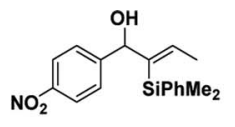

3a
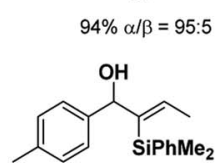

3d

$84 \% \alpha / \beta=91: 9$

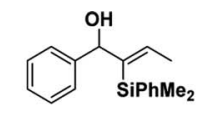

3b

$87 \% \alpha / \beta=92: 8$

$3 \mathrm{e}$

$76 \% \alpha / \beta=88: 12$

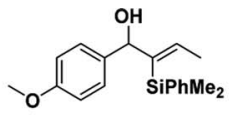

$3 c$

$71 \% \alpha / \beta=95: 5$

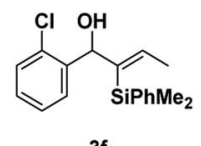

$3 f$

$82 \% \alpha / \beta=90: 10$

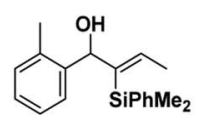

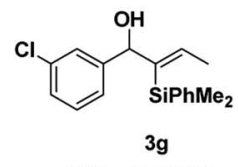

$85 \% \alpha / \beta=90: 10$

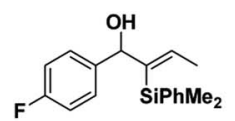

3j

$80 \% \alpha / \beta=95: 5$

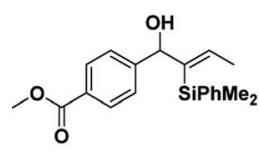

$3 \mathrm{~m}$

$63 \% \alpha / \beta=94: 6$

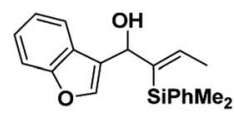

$3 p$

$82 \% \alpha / \beta=95: 5$

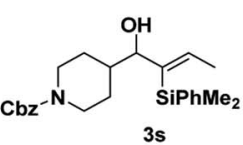

$84 \% \alpha / \beta=88: 12$

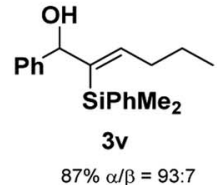

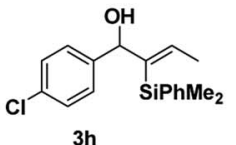

$90 \% \alpha / \beta=91: 9$

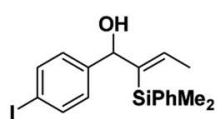

3k

$87 \% \alpha / \beta=95: 5$

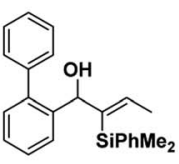

$3 n$

$79.3 \% \alpha / \beta=86: 14$

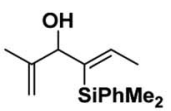

$3 q$

$75 \% \alpha / \beta=86: 14$

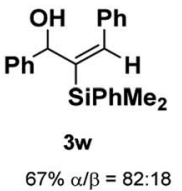

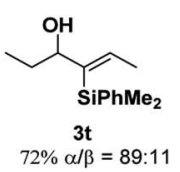

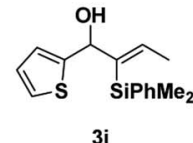

$3 \mathbf{i}$
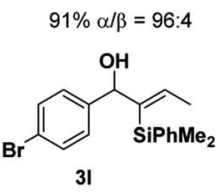

$80 \% \alpha / \beta=96: 4$

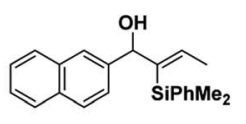

$89 \% \alpha / \beta=93: 7$
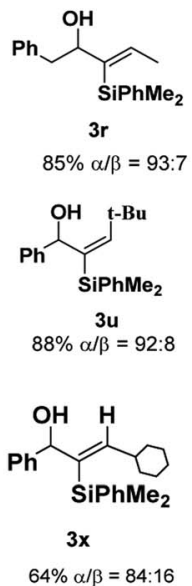

${ }^{a}$ Reaction conditions: 1a $(0.24 \mathrm{mmol}), 2(0.2 \mathrm{mmol}), \mathrm{CpRu}\left(\mathrm{Ph}_{3} \mathrm{P}\right)_{2} \mathrm{Cl}$ ( $2 \mathrm{~mol} \%)$, in anhydrous $\mathrm{CH}_{2} \mathrm{Cl}_{2}(2 \mathrm{~mL})$ under $\mathrm{Ar}$ at room temperature for $12 \mathrm{~h} .{ }^{b}$ Isolated yields. ${ }^{c}$ Determined by ${ }^{1} \mathrm{H}$ NMR analysis of the crude reaction mixtures.

regio-selective and stereo-selective for the preparation of $\alpha$ vinylsilanes from unbiased and unsymmetrical internal alkynes. 


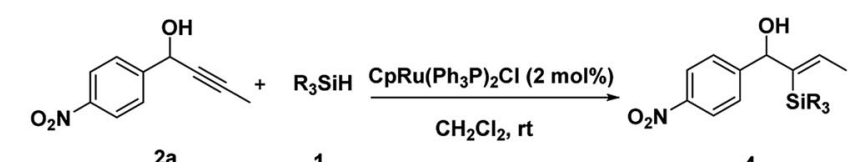

$2 a \quad 1$

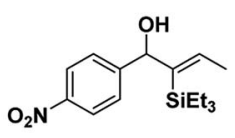

$4 a$

$94 \% \alpha / \beta=95: 5$

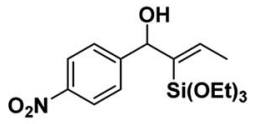

4b

$61 \% \alpha / \beta=91: 9$<smiles>C/C=C(\c1ccc([N+](=O)[O-])cc1)C(C)(O)C(C)(C)C</smiles>

$60 \% \alpha / \beta=2: 1$

Scheme 2 Alternative silane scope.

\section{Results and discussion}

We initiated our studies with the hydrosilylation reaction of 1(4-nitrophenyl) but-2-yn-1-ol 2a and the easily available $\mathrm{PhMe}_{2} \mathrm{SiH} 1 \mathrm{a}$ in the presence of a Ru complex. Interestingly, when the reaction was carried out with $\mathrm{CpRu}\left(\mathrm{Ph}_{3} \mathrm{P}\right)_{2} \mathrm{Cl}(5 \mathrm{~mol} \%)$ in THF for $12 \mathrm{~h}$, 3a was obtained in 68\% yield with good regioselectivity $(\alpha / \beta=82: 18)$ (Table 1 , entry1). Then solvent screening was conducted, when the reaction was conducted in $\mathrm{CH}_{2} \mathrm{Cl}_{2}$, the best result was obtained (94\% yield with excellent regioselectivity $(\alpha / \beta=95: 5)$ ) (entries $2-4)$. Other catalysts, such as $\left[\left\{\mathrm{RuCl}_{2}(p \text {-cymene })\right\}_{2}\right],[\mathrm{Cp} * \mathrm{RuCl}]_{4}$, reduced the yield of $\mathbf{3 a}$ with poor regioselectivity compared to $\mathrm{CpRu}\left(\mathrm{Ph}_{3} \mathrm{P}\right)_{2} \mathrm{Cl}$ (entries 5

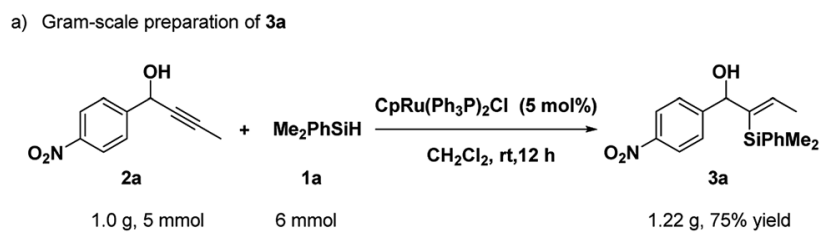

b) The coupling reaction of vinylsilane $3 z a$

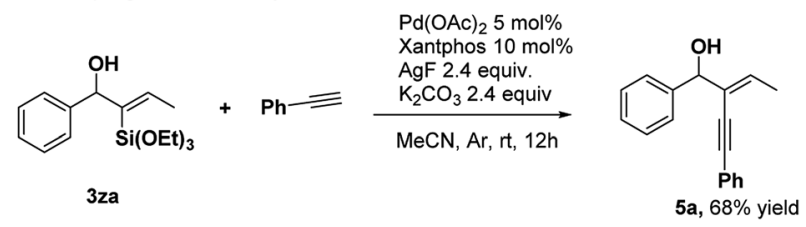

c) The epoxidation reaction of vinylsilane $\mathbf{3 a}$

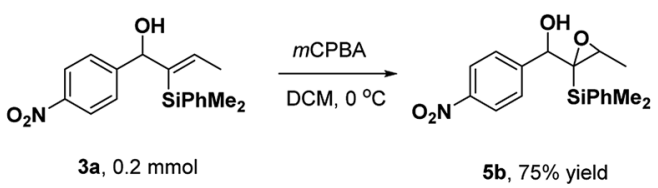

d) The protodesilylation reaction of vinylsilane $\mathbf{3 a}$

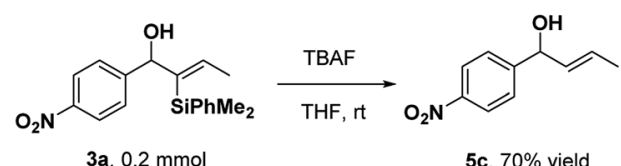

Scheme 3 Gram-scale experiment and transformations of the products. and 6). To further improve the reaction efficiency, the loading amount of the catalyst was investigated. When we reduced the loading amount of the $\mathrm{CpRu}\left(\mathrm{Ph}_{3} \mathrm{P}\right)_{2} \mathrm{Cl}$ from $5 \mathrm{~mol} \%$ to $2 \mathrm{~mol} \%$, the reaction also produced $3 \mathbf{a}$ in excellent yield (94\%) and excellent regioselectivity $(\alpha / \beta=95: 5)$ (entry 7$)$. However, when $1 \mathrm{~mol} \% \mathrm{CpRu}\left(\mathrm{Ph}_{3} \mathrm{P}\right)_{2} \mathrm{Cl}$ was used in the hydrosilylation reaction, the yield of $\mathbf{3 a}$ was slightly decreased (entry 8). Then this reaction was carried out in air atmosphere, the yield and regioselectivity slightly decreased (entry 9). When $5 \mathrm{~mol} \%$ $\left[\mathrm{CpRu}\left(\mathrm{Ph}_{3} \mathrm{P}\right)(\mathrm{tht})\right] \mathrm{BF}_{4}$ was applied, we got the poor regioselectivity $(\alpha / \beta=22: 78)$ (entry 10 ), it showed the $\mathrm{Cl}$ ligand played a crucial role. Briefly, the optimal results could be obtained when 1-(4-nitrophenyl) but-2-yn-1-ol $2 \mathrm{a}(0.2 \mathrm{mmol})$ and $\mathrm{PhMe}_{2} \mathrm{SiH} 1 \mathrm{a}(0.24 \mathrm{mmol}, 1.2$ equiv.) were treated with $2 \mathrm{~mol} \%$ $\mathrm{CpRu}\left(\mathrm{Ph}_{3} \mathrm{P}\right)_{2} \mathrm{Cl}$ in $\mathrm{CH}_{2} \mathrm{Cl}_{2}$ at room temperature for $12 \mathrm{~h}$.

With the optimized conditions in hand, we examined the scope of different propargyl alcohols 2 in the hydrosilylation reaction with $\mathrm{PhMe}_{2} \mathrm{SiH}$ 1a (Table 2). Substrates containing electron-withdrawing groups, such as nitro and halides, at the phenyl moiety of propargyl alcohols were well tolerated under the standard reaction conditions $(\mathbf{3 a}, \mathbf{3} \mathbf{f}-\mathbf{3 h}$, and $\mathbf{3 j} \mathbf{j} \mathbf{3} \mathbf{l})$. A similar level of efficiency was observed when substrates having phenyl, $p$-tolyl, $o$-tolyl, and 1,1'-biphenyl groups (3b, 3d, 3e, and 3n), while some other electron-rich substrates provided the desired products in decreased yields (3c). In addition, the desired products were obtained in higher yields and better regio-selectivity when substituents, such as methyl and chloride, were introduced at the para position of the phenyl moiety (3d vs. 3e, and $3 \mathbf{h} v s$. 3f). The tolerance of the reaction with active groups such as halides in the substrates meant that they could be further transformed into other functional groups. When an ester group was placed at the para position of phenyl ring, 3m was obtained in $63 \%$ yield, and it seemed that the carbonyl may participate in coordination. Furthermore, substrates bearing other heteroaryl groups, such as thiophene and benzofuran, also could react with 1a to produce the desired product in good yields with excellent regio-selectivity (3i and 3p). Significantly, replacing the phenyl moiety of the propargyl alcohols with vinyl, benzyl, N-protected piperidyl and alkyl, the hydrosilylation reaction also underwent smoothly with satisfactory results (3q-3t). While the introduction of bulkier groups (such as tert-butyl and $\mathrm{Ph}$ ) in the $\mathrm{R}_{2}$ moiety of the substrates 
provided the different stereo-selective products in good yields $(3 \mathbf{u}, 3 \mathbf{w})$, which was different from Fürstner's work. ${ }^{9 a}$

Moreover, when $\mathrm{Et}_{3} \mathrm{SiH}$ was used, the hydrosilylation of $2 \mathbf{a}$ proceeded with excellent result $(\alpha / \beta=95: 5,94 \%$ yield $)$ (Scheme 2). Given the poor reactivity of alkylsilanes toward a variety of synthetically transformations, we extended the method to more reactive and operationally convenient alkyoxysilanes. Hydrosilylation of 2a with triethoxylsilane was performed under standard conditions and provided the desired product $4 \mathrm{~b}$ in $61 \%$ yield with excellent regioselectivity. However, hydrosilylation of $\mathbf{2 a}$ with $t$-BuMe ${ }_{2} \mathrm{SiH}$ produced desired product $4 \mathrm{c}$ in $60 \%$ yield with poor regio-selectivity.

To assess the efficiency and potential applications of this method, we carried out gram-scale preparation and transformations of the products (Scheme 3). When propargyl alcohol 2a (1.0 g, $5 \mathrm{mmol})$ was used, the reaction afforded the corresponding product $\mathbf{3 a}$ in $75 \%$ yield. Besides, there were few works about the transformation of $\alpha$-hydroxy alkynylsilanes by coupling reactions to date. ${ }^{9 \boldsymbol{d}}$ In our work, the coupling of vinylsilane 3za and phenylacetylene could provide the product $5 \mathbf{a}$ in good yield.$^{10}$ The epoxidation of 3a with $m$ CPBA resulted in product $\mathbf{5 b}$. Furthermore, vinylsilane $\mathbf{3 a}$ could be converted to trans-olefin $\mathbf{5 c}$ by tetrabutylammonium fluoride (TBAF) in $70 \%$ yield at room temperature (Scheme 3d).

\section{Conclusions}

In summary, we reported a mild and efficient rutheniumcatalyzed hydrosilylation of internal alkynes. This method enables the efficient preparation of vinylsilanes in good to excellent yields with highly regio-selectivity and stereoselectivity. Its mild reaction conditions mean that this approach is also compatible with various functional groups. We also achieved the gram-scale production and some transformations of vinylsilanes, which further underscored the synthetic utility and versatile applicability of this method.

\section{Conflicts of interest}

There are no conflicts to declare.

\section{Acknowledgements}

We gratefully acknowledge financial support from the National Natural Science Foundation of China (81620108027, 21632008 and 81602975), the Major Project of Chinese National Programs for Fundamental Research and Development (2015CB910304)

\section{Notes and references}

1 (a) T. A. Blumenkopf and L. E. Overman, Chem. Rev., 1986, 86, 857; (b) E. Langkopf and D. Schinzer, Chem. Rev., 1995, 95, 1375; (c) I. Ojima, Z. Li and J. Zhu, The Chemistry of Organic Silicon Compounds. Wiley, Hoboken, 2003, p. 1687; (d) I. Beletskaya and C. Moberg, Chem. Rev., 1999, 99, 3435; (e) M. Suginome and Y. Ito, Chem. Rev., 2000, 100, 3221; (f) D. S. W. Lim and E. A. Anderson, Synthesis, 2012, 44, 983; (g) M. Zaranek, B. Marciniec and P. Pawluć, Org. Chem. Front., 2016, 3, 1337.

2 (a) H. Brunner, Angew. Chem., Int. Ed., 2004, 43, 2749; (b) B. M. Trost and Z. T. Ball, Synthesis, 2005, 6, 853; (c) L. Iannazzo and G. A. Molander, Eur. J. Org. Chem., 2012, 2012, 4923; (d) A. K. Roy, Adv. Organomet. Chem., 2008, 55, 1; (e) Q. Q. Xuan, C. L. Ren, L. Liu, D. Wang and C. Li, Org. Biomol. Chem., 2015, 13, 5871.

3 (a) S. Schwieger, R. Herzog, C. Wagner and D. Steinborn, J. Organomet. Chem., 2009, 694, 3548; (b) Y. Sumida, T. Kato, S. Yoshida and T. Hosoya, Org. Lett., 2012, 14, 1552; (c) T. Sanada, T. Kato, M. Mitani and A. Mori, Adv. Synth. Catal., 2006, 348, 51; (d) T. Konno, K. Taku, S. Yamada, K. Moriyasu and T. Ishihara, Org. Biomol. Chem., 2009, 7, 1167; (e) C. Belger and B. Plietker, Chem. Commun., 2012, 48, 5419; $(f)$ T. Murai, E. Nagaya, F. Shibahara, T. Maruyama and H. Nakazawa, J. Organomet. Chem., 2015, 794, 76; $(g)$ W. Guo, R. Pleixats, A. Shafir and T. Parella, Adv. Synth. Catal., 2015, 357, 89; (h) M. Planellas, W. Guo, F. Alonso, M. Yus, A. Shafir, R. Pleixats and T. Parella, Adv. Synth. Catal., 2014, 356, 179.

4 (a) C. A. McAdam, M. G. McLaughlin, A. J. Johnston, J. Chen, M. W. Walter and M. Cook, Org. Biomol. Chem., 2013, 11, 4488; (b) S. Sueki and Y. Kuninobu, Chem. Commun., 2015, 51, 7685; (c) R. Cano, M. Yus and D. J. Ramón, ACS Catal., 2012, 2, 1070; (d) F. Monteil, I. Matsuda and H. Alper, J. Am. Chem. Soc., 1995, 117, 4419; (e) D. A. Rooke and E. M. Ferreira, Org. Lett., 2012, 14, 3328; $(f)$ Y. Kim, R. B. Dateer and S. Chang, Org. Lett., 2017, 19, 190; $(g)$ A. Rivera-Hernandez, B. J. Fallon, S. Ventre, C. Simon, M. H. Tremblay, G. Gontard, E. Derat, M. Amatore, C. Aubert and M. Petit, Org. Lett., 2016, 18, 4242; (h) P. Gao, W. Zhang and Z. Zhang, Org. Lett., 2016, 18, 5820.

5 (a) B. M. Trost and Z. T. Ball, J. Am. Chem. Soc., 2001, 123, 12726; (b) L. N. Lewis, K. G. Sy, G. L. Bryant and P. E. Donahue, Organometallics, 1991, 10, 3750; (c) R. Takeuchi, S. Nitta and D. Watanabe, J. Org. Chem., 1995, 60, 3045; (d) Y. Na and S. Chang, Org. Lett., 2000, 2, 1887; (e) A. Sato, H. Kinoshita, H. Shinokubo and K. Oshima, Org. Lett., 2004, 6, 2217; $(f)$ K. H. Huang and M. Isobe, Eur. J. Org. Chem., 2014, 2014, 4733; $(g)$ Z. Mo, J. Xiao, Y. Gao and L. Deng, J. Am. Chem. Soc., 2014, 136, 17414; $(h)$ C. Z. Wu, W. J. Teo and S. Z. Ge, ACS Catal., 2018, 8, 5896; (i) W. J. Teo, C. Wang, Y. W. Tan and S. Z. Ge, Angew. Chem., Int. Ed., 2017, 56, 4328; (j) X. Y. Du, W. J. Hou, Y. L. Zhang and Z. Huang, Org. Chem. Front., 2017, 4, 1517. 6 (a) Y. Kawanami, Y. Sonoda, T. Mori and K. Yamamoto, Org. Lett., 2002, 4, 2825; (b) C. Menozzi, P. I. Dalko and J. Cossy, J. Org. Chem., 2005, 70, 10717; (c) L. W. Chung, Y. D. Wu, B. M. Trost and Z. T. Ball, J. Am. Chem. Soc., 2003, 125, 11578; (d) E. A. Ilardi, C. E. Stivala and A. Zakarian, Org. Lett., 2008, 10, 1727.

7 (a) B. M. Trost and Z. T. Ball, J. Am. Chem. Soc., 2004, 126, 13942; (b) B. M. Trost and Z. T. Ball, J. Am. Chem. Soc., 2005, 127, 17644; (c) Y. Kawasaki, Y. Ishikawa, K. Igawa and K. Tomooka, J. Am. Chem. Soc., 2011, 133, 20712; (d) D. A. Rooke and E. M. Ferreira, Angew. Chem., Int. Ed., 
2012, 51, 3225; (e) R. A. García, R. J. A. Romero, P. Mauleón, R. Gómez Arrayás and J. C. Carretero, J. Am. Chem. Soc., 2015, 137, 5506.

8 B. M. Trost, Z. T. Ball and T. Jöge, Angew. Chem., Int. Ed., 2003, 42, 3537.

9 (a) S. M. Rummelt, K. Radkowski, D. Roşca and A. Fürstner, J. Am. Chem. Soc., 2015, 137, 5506; (b) T. G. Frihed and
A. Fürstner, Bull. Chem. Soc. Jpn., 2016, 89, 135; (c) D. Roşca, K. Radkowski, L. M. Wolf, M. W. Richard Goddard, W. Thiel and A. Fürstner, J. Am. Chem. Soc., 2017, 139, 2443; (d) N. Huwyler, K. Radkowski, S. M. Rummelt and A. Ferstner, Chem.-Eur. J., 2017, 23, 12412.

10 Z. S. Ye, M. C. Liu, B. D. Lin, H. Y. Wu, J. C. Ding and J. Cheng, Tetrahedron Lett., 2009, 50, 530. 